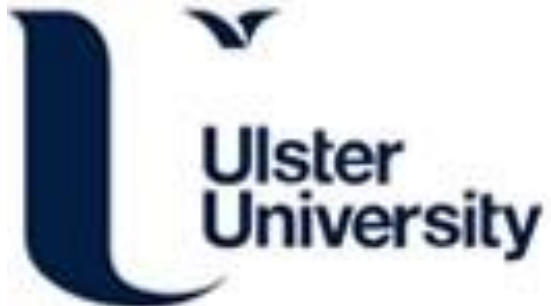

The experience of fatigue for people living with hepatitis $C$

Glacken, M., Coates, V., Kernohan, G., \& Hegarty, J. (2003). The experience of fatigue for people living with hepatitis C. Journal of Clinical Nursing, 12(2), 244-252. https://doi.org/10.1046/j.1365-2702.2003.00709.x

Link to publication record in Ulster University Research Portal

\section{Published in:}

Journal of Clinical Nursing

Publication Status:

Published (in print/issue): 09/05/2003

DOI:

10.1046/j.1365-2702.2003.00709.x

\section{Document Version}

Publisher's PDF, also known as Version of record

\section{General rights}

Copyright for the publications made accessible via Ulster University's Research Portal is retained by the author(s) and / or other copyright owners and it is a condition of accessing these publications that users recognise and abide by the legal requirements associated with these rights.

\section{Take down policy}

The Research Portal is Ulster University's institutional repository that provides access to Ulster's research outputs. Every effort has been made to ensure that content in the Research Portal does not infringe any person's rights, or applicable UK laws. If you discover content in the Research Portal that you believe breaches copyright or violates any law, please contact pure-support@ulster.ac.uk. 


\title{
The experience of fatigue for people living with hepatitis $C$
}

\author{
MICHÈLE GLACKEN BSc, PhD, RGN, RM \\ Lecturer/BNS Co-ordinator, University of Dublin, Trinity College, School of Nursing and \\ Midwifery Studies, Trinity Centre for Health Sciences, St James's Hospital, Dublin, Ireland \\ VIVIEN COATES BA, MPhil, DPhil, RGN \\ Senior Lecturer in Nursing, University of Ulster at Coleraine, Coleraine, UK \\ GEORGE KERNOHAN BSc, PhD \\ Professor of Health Research, University of Ulster at Jordanstomn, Shore Road, Nemtomnabbey, UK \\ JOHN HEGARTY MD, FRCPI, FRCP \\ Director of National Liver Transplant Unit, St Vincent's Hospital, Elm Park, Dublin, Ireland \\ Accepted for publication 6 Fune 2002
}

\section{Summary}

- Hepatitis C affects approximately $3 \%$ of the world population, with fatigue being acknowledged as the cardinal symptom. Despite growing recognition that hepatitis $\mathrm{C}$ fatigue impacts in a negative manner on quality of life, at the time of this study no empirical information existed regarding the nature of this fatigue or the way in which it affects a person's life. Such information is needed to enable nurses to engage in appropriate sensitive symptom management which is the core nursing activity with this population, as to date there is no vaccine or widely effective pharmacological therapy.

- The aim of the study was to ascertain the nature of hepatitis $\mathrm{C}$ fatigue.

- A qualitative approach using a grounded theory approach was employed. Theoretical sampling generated 28 participants for in-depth interview. Data analysis consisted of three coding processes, each type of coding having its own purpose and method. Ethical approval was obtained, both from the principal author's academic institution and the participating health care institution.

- Hepatitis $\mathrm{C}$ fatigue emerged as being multidimensional in nature, with both acute and chronic versions existing.

- The hepatology community is beginning to acknowledge the significant prevalence of hepatitis $\mathrm{C}$ fatigue. This study provides a valuable insight into its nature. This information can serve as resource for practitioners in their development of interventions to enable the hepatitis $\mathrm{C}$ virus population live with fatigue in a proactive manner.

Keymords: fatigue, grounded theory, hepatitis $\mathrm{C}$ virus.

Correspondence to: Michele Glacken, 61 Fforster Lamn, Ballydowd

Manor, Lucan, Co. Dublin, Ireland (tel.: +353 1 6214278; e-mail:

glackenm@tcd.ie). 


\section{Introduction}

Hepatitis C is one out of six viruses (A, B, C, D, E and $\mathrm{G})$ that together account for the majority of cases of viral hepatitis. It can evoke a benign, asymptomatic disorder with a mild course but may also cause progressive liver disease, cirrhosis and primary liver cancer (Dana et al., 1994; Tong et al., 1995; Strader \& Seeff, 1996; Fattovich et al., 1997; Hoofnagle, 1997). The hepatitis C virus' (HCV) propensity for chronicity is unfortunately one of its most notable characteristics, with approximately $85 \%$ of those infected developing chronic infection (Hoofnagle, 1997). There is a wide variation in its prevalence worldwide and the estimated global incidence is $3 \%$, or approximately 200 million people (World Health Organisation, 1997). The most efficient transmission of $\mathrm{HCV}$ is associated with percutaneous exposure to blood, but this does not account for all cases. To date no vaccine or pharmacological treatment capable of achieving widespread sustained viral clearance has been developed.

Fatigue is a universal experience. It occurs in the old and in the young, in humans and in animals. It varies in intensity and occurs under different conditions and in different situations (Eidelman, 1980). There is no interdisciplinary definition or common mechanism for classifying fatigue, which is not always an unpleasant sensation or related to a clinical condition. Indeed, for the vast majority of people it serves a vital protective function, and in this context is considered to be pleasant and welcome. Fatigue ceases to be 'normal' when a person starts to view it as a problem and begins the process of asking for help to deal with it (Wessely et al., 1998). From a health professional's perspective, it can be a precursor, product or a disease entity itself. It is acknowledged that fatigue per se does not kill but that it can impair a person's quality of life. Despite its universality, varying status and impact, it remains one of the least understood and neglected symptoms by health professionals. Lewis \& Wessely (1992) believe that it may be a victim of a variant of Tudor-Hart's inverse care law - 'an inverse interest law' that is, the more the ordinary a condition, the less the professional interest.

\section{FATIGUE IN CHRONIC LIVER DISEASE}

Although it is becoming increasingly acknowledged that fatigue is prevalent and a key determining factor of the health-related quality of life of individuals with chronic liver disease, to date there has been a lack of any appreciable research interest in this area (Huet \& Deslauriers, 1996; Huet et al., 1996; Cauch-Dudek et al., 1998; Younossi et al., 1998; Prince et al., 1999). The consequence of the latter is a general lack of understanding regarding the aetiology, correlates and/or treatment of liver disease fatigue. Fatigue is regarded as 'a riddle wrapped in a mystery inside an enigma' by the majority of hepatology health professionals (Jones, 1995, p. 1606). Although no definitive confirmation had been achieved, the pioneering physiology researchers in this area have advanced a number of potential causes for liver diseaserelated fatigue, such as decreased levels of corticotrophinreleasing hormone, hypercytokinaemia, serum acylcarnitine and hyperammonaemia (Dietrich et al., 1990; Swain \& Maric, 1995, 1997; Plevris \& Blair, 1997; Kuratsune et al., 1998).

At the time of this research, possibly reflecting the relative modernity of the disease, no empirical study could be located that had hepatitis $\mathrm{C}$ associated fatigue as its prime focus, although it was widely recognized to exist by clinicians and patients alike (Dolan, 1997; Mahony, 1998; Spray, 1998). Frequent but superficial reference was made to it as the cardinal symptom that the symptomatic population complained of, variably described as lethargy, malaise, lack of energy or easy fatigability (Desmet et al., 1994; Di Bisceglie et al., 1995; Shakil et al., 1995; Hoofnagle, 1997). Retrospective chart reviews placed its prevalence between $45 \%$ and $66 \%$ (Lee et al., 1997; Kenny-Walsh, 1999). A descriptive-exploratory study was subsequently carried out with members of the Irish hepatitis $\mathrm{C}$ population that confirmed the presence of fatigue and indicated that it had a negative impact on their health-related quality of life (Glacken et al., 2001). The decision to focus solely on the hepatitis $\mathrm{C}$ population was influenced by the fact that compared with any of the other hepatitis viruses, a substantial proportion $(70-80 \%)$ of those infected go on to develop chronic $\mathrm{HCV}$ and therefore are at risk of experiencing fatigue, as this symptom is a recognized accompaniment of chronic hepatitis C infection. Secondly, there is no indication either empirically or anecdotally that those with any of the other hepatitis viruses experience fatigue to an appreciable extent.

In view of the fact that to date there is no vaccine or widely available effective pharmacological treatment for $\mathrm{HCV}$, it was clear that fatigue management would become one of the core nursing activities with patients and their families in the future. In order to engage effectively in this activity, an in-depth understanding of the experience of fatigue was required. 


\section{Methodology}

RESEARCH QUESTION

What is the nature of the fatigue that individuals with hepatitis $\mathrm{C}$ experience?

\section{RESEARCH DESIGN}

Acknowledging the immaturity of the concept of fatigue in the hepatology literature and the questions set for exploration, a qualitative research approach was adopted, namely grounded theory. Qualitative methods recognize that a concept cannot be divorced from its context. Monk's (1989) study of fatigue in rheumatoid arthritis clearly delineated that the context of fatigue is crucial to its definition because of its quality-giving characteristics. Grounded theory was chosen over other qualitative methodologies because of its recognized suitability for eliciting processes and changes over time, allowing appreciation of the possible evolving nature of the concept under examination (Gift, 1997). An earlier exploratory study indicated that this may be a feature of hepatitis C fatigue (Glacken et al., 2001). The techniques of grounded theory also accommodate the formation and linking of categories, identification of negative cases and comparison of different contexts or populations (Morse et al., 1997). It was believed that these features would all contribute to yielding a comprehensive description and understanding of hepatitis $\mathrm{C}$ associated fatigue. The methodological principles of grounded theory as advanced by Strauss \& Corbin (1990) were followed.

\section{SAMPLE}

In keeping with grounded theory, theoretical sampling was employed. In contrast to other forms of sampling, the principal concern of sampling was with the representativeness of the emerging concepts in their varying forms. The researcher was looking for events and incidents that were indicative of the phenomena being studied, and was not counting individuals. The sampling process was directed by the aim of each of the three coding procedures - open, axial and selective. Notable features of the process were its cumulative nature and that its depth of focus increased as the research study progressed. Theoretical saturation was achieved following 26 interviews and secondary analysis of the transcripts of two interviews previously carried out by the principal author in an earlier study (Glacken et al., 2001) (Table 1).

Eight out of 28 participants were male, with participants varying in age from 36 to 64 years. The majority
Table 1 Theoretical sampling process

\begin{tabular}{lcc}
\hline & Invited to participate & Interviewed \\
\hline Open coding (time 1) & 15 & 12 \\
Axial coding (time 2) & 8 & 8 \\
Selective coding (time 3) & 9 & 6 \\
Secondary analysis \\
$\quad \begin{array}{l}\downarrow \\
\text { Theoretical saturation }\end{array}$ & & $(2)$ \\
& & 28 \\
\hline
\end{tabular}

$(n=24)$ were viraemic. Primarily, participants were infected with $\mathrm{HCV}$ as a result of receiving infected blood/plasma transfusions or through needle sharing during the use of illicit intravenous drugs. In two cases the source of HCV could not be established.

\section{ETHICS}

Ethical issues in relation to human research in general, which the International Council of Nurses (1996) have delineated as the right not to be harmed, right of full disclosure, right of self-determination, right of privacy and confidentiality, were respected. Ethical approval was received from the principal author's associated university and from the hospital which served as the source of access to participants.

\section{DATA GENERATION AND ANALYSIS}

The mode of data generation employed was in-depth interviewing, although in reality, as in any grounded theory study, data generation was not distinct from data analysis. In keeping with interviewing in the interactionist tradition, the primary goal was to give authentic insight into participants' experiences (Silverman, 1993; Charmaz, 1995). The interviews were tape-recorded where the setting and participants permitted $(n=24)$; otherwise notes were taken and the interview written up immediately afterwards $(n=4)$. The average length of interviews was 80 minutes (range 50-180). A minimum of an additional 30 minutes was spent with each of the participants as a debriefing session following the interviews. These sessions were not recorded. Data analysis consisted of three coding processes, each type of coding having its own purpose and methodology. With the exception of the very early stages in the study, the coding processes were not always employed as separate entities in the analysis and therefore the researcher was employing at times all three types of coding concurrently. Two analytical procedures served as the mutual bedrock for all the coding processes, namely 
making constant comparisons and asking questions of the data. The questions generated were subsequently posed as hypotheses, with verification being sought in the data. It is believed that these procedures enabled the researcher to give the emerging concepts depth and specificity. Throughout the study, the first author kept written memos and used diagrams to help formulate her thoughts and make visual links between emerging categories.

\section{TRUSTWORTHINESS OF FINDINGS}

The trustworthiness of the data was established through a number of strategies: member checks, development of an audit trail of the analytical processes, continuous use of Paterson's (1994) reactivity analysis framework and enlisting the assistance of an individual who was Master's prepared and had expert knowledge of the hepatitis $\mathrm{C}$ population to challenge the researcher on the robustness of the categories that were being advanced. This latter strategy resulted in pursuing some different avenues so that more complete interpretations of the data could be advanced.

\section{Findings}

The research question posed was in relation to the nature of the fatigue that the hepatitis $\mathrm{C}$ population experience. The majority of the participants were unable to share this knowledge in a nominal form but only through the use of metaphors, comparisons with the norm or as a precursor of a reduction in an activity or a treasured role:

It is like on one hand if someone is pouring concrete into you and it is weighing you down but on the other hand it is like feeling almost like you are coming out of an anaesthetic; you know you are in those two worlds, trying to grasp onto the normal world and not being able to leave that other world.

This difficulty in articulating the fatigue experience, and hence the use of metaphors to demonstrate its qualities has also emerged in other studies (Ferrell et al., 1996; Pearse \& Richardson, 1996; Ream \& Richardson, 1997).

The major sentiment that emerged from the data and encapsulated participants' perceptions of the nature of the fatigue was that it was a pernicious experience in its onset, nature, dimensions and severity. No universal fatigue trajectory emerged, with some participants being able to isolate an exact date for its onset and detail its subsequent course:

In 1992, things changed. I started to get aches and pains and tiredness and the tiredness was not anything to do with me feeling low or anything it was different. It has just progressed over the years.
Others, however, experienced its evolution as a more insidious process.

\section{NATURE OF FATIGUE}

The fatigue was considered by participants to be discernible from their understanding of 'normal fatigue' in that it was arresting, ageing, impregnable and invincible, the difference frequently being likened to 'night and day':

You cannot fight it; it is not a tiredness that you can fight like a normal tiredness. A normal tiredness, you can fight it and get a second wind or if you had a few cups of coffee, it would keep you going. None of this works with this tiredness.

The most distinguishing feature of the fatigue, that of two distinct types, emerged as data generation and coding progressed. This led to further theoretical sampling for verification of their existence. The two distinct classes of fatigue will be subsequently referred to as chronic and idiopathic:

There are two levels of tiredness, there is just ordinary tiredness that I think everybody has and there is... what I call the 'sick tiredness'. It is like you are not just tired, but you are sick, but you have not got any sickness. Yes, you feel sick, you feel like you have had a really bad dose of the flu, and you are trying to come out of it, but you are not coming out of it, but you haven't had the flu, you know what I mean. and it is like somebody has poured a jug of concrete into me and there is this weight that I cannot overcome.

There are two kinds ... Tiredness and exhaustion and where as I say the exhaustion doesn't come all the time to you. I could be just tired. With the exhaustion you feel defeated...It is a weird feeling. You just feel that your whole body just breaks down. It is not your own. Your head is there but your body is not your own. You just want to do things but you cannot.

One of the most contrasting features of the two types of fatigue was in terms of the property, status, whose dimensions ranged from permanent to temporary. Chronic fatigue seemed to be a permanent feature in participants' lives:

I am permanently tired. It is present even on wakening every morning.

I am like an old engine trying to get started in the morning, trying to stoke myself up. It could take me 2 or 3 hours to get going.

The intensity of the chronic fatigue appeared to vary. For some, a distinct daily fatigue trajectory could be outlined, with span of severe fatigue lasting a number of hours, 
where for others it was a constant low grade fatigue that was manageable if certain strategies were employed, and provided the flavour or background to their 'good days'.

In contrast, the temporary fatigue was a transient but recurring fatigue in their lives, which had two equally distressing features. First was its unpredictability both in occurrence and duration, and second was its intensity, which was so acute that it had the ability to strip participants completely of their feeling of control. The consequence was that life and all it entailed at that particular time had to be put on hold until the idiopathic fatigue was defunct for that particular occasion:

I might have a couple of months; 3 or 4 months going grand or maybe 6 weeks even, fine. Full of beans and I can do anything and then all of a sudden, bang and there it is ... and then you wake up one morning, and you say 'Oh, God, I feel much better today, and it is gone'. I don't know what triggers it to go. I can feel it coming on sometimes but it just goes away without warning and I don't know why it just goes away. Whether you have had enough of your resting, time to rejuvenate or whatever. I don't know, I really don't know...don't understand it, because there is nothing, nothing different going on [in your life].

The oppressive nature of this fatigue was compared with being in a 'fog' that one was struggling to get out or experiencing a very hot climate with its accompanying humidity, and when the idiopathic fatigue disappeared, it was like breathing in fresh air. It was considered to be unpleasant because of its uncontrollable nature and viewed as so intrusive that one participant felt she would not want to live if it was present all the time. The onset, particularly if it was physically orientated, seemed to have the capacity to demand instant attention from those experiencing it, frequently articulated as desperate need to lie down. One questionnaire explained, 'I just need to lie down. I just have to go to bed'.

Although both types of fatigue were different, from a location perspective, hepatitis $\mathrm{C}$ associated fatigue was unanimously experienced as a whole body feeling. It was a fatigue that penetrated the entire body, as if it emanated from the very core of their being. This feature differentiated it from participants' conceptualization of normal fatigue, which manifests itself locally:

The fatigue seems to invade every crevice of your body, everything is affected.

\section{DIMENSIONS}

Both types of fatigue were multidimensional in nature, with physical, cognitive and affective dimensions, although their significance in terms of their degree of intensity were unique to the individual. Although it was evident from the participants that the physical dimension of their fatigue was the most disconcerting.

\section{PHYSICAL DIMENSION}

A feeling of heaviness was the over-arching way fatigue manifested itself, participants at times believing that they could 'collapse with the weight' of their bodies:

It is a feeling of heaviness. I just feel I am going to collapse with the weight of my body. It is like something continually dragging out of you.

Weakness also manifested itself as an intrinsic component of the physical dimension. Weakness is not regarded as a feature of the fatigue experienced by healthy populations but is accepted as an inherent feature of the fatigue of some unhealthy populations, such as those with various carcinomas (Glaus, 1996), for example:

When I get tired I have a terrible weakness. I shake like a leaf.

The fatigue was also discernible by its draining capacity and ability to sap participants of their energy:

When I was depressed, I had this sort of paralysis,

I couldn't do things, had lost interest but I have not now. I still have all my interests but I have not the energy to do them and I suppose that is physical.

I play guitar and banjo and there are days when

I wouldn't have the energy to pick them up.

Similarly, it also robbed participants of stamina, which subsequently curtailed their ability to engage in certain activities. An aching sensation also accompanied the fatigue, with participants recounting that 'every part of me aches'. It appeared difficult for them to discern the origin of this sensation, that is, whether it was skeletal or muscular in origin, although it was acknowledged that the fatigue had the capacity to activate or augment the severity of existing pain:

When I get tired, I can feel the pain gradually coming on. I refer to it as liver pain.

\section{COGNITIVE DIMENSION}

Hepatitis C fatigue also has a well-defined cognitive dimension, although the majority of participants attributed less significance to this. The reasons were not clear but could be because the fatigue manifested itself less frequently or intensely in this manner or more control could be achieved over it, as certain activities could be employed to neutralize its effects, such as writing things down to offset forgetfulness. Forgetfulness and lack of 
concentration appeared the most universal aspects of the cognitive dimension:

Stupid is the only word for it. Thick, kinda. A bit forgetful as well. It is very annoying. I have no concentration. I cannot learn during that time. I cannot read for any length of time, because. I just sort of lose it a bit.

According to one man, it was not a physical fatigue form but was more 'a mental thing really - it is like a few notches have been chopped off your IQ'.

\section{AFFECTIVE SENSATION}

Participants were judiciously conscious of the affective dimension of their fatigue experience as they found this aspect particularly distressing to tolerate. An array of emotions appeared to be entangled in their fatigue such as anger, frustration and anxiety:

Something comes upon me (when I am tired). People say I get a bit of a temper. Sometimes I am so bad tempered... what would come out of my mouth would shock me, myself.

Although the goal of the methodology employed was not to determine causality, it did seem that the fatigue experienced could be an instigator of 'depressed mood'.

\section{SEVERITY}

Participants did not judge the severity of the fatigue experience solely by its intensity. Instead, severity was considered a combination of intensity, duration and frequency. The fatigue appeared to be tolerated by them if it did not require them to relinquish total control of their daily activities. Conversely, it was perceived as intolerable and severe in nature when its presence required them to relinquish control over the totality of their daily activities:

You know I could put up with this fatigue...even every day, if I knew it would only be there for an hour or two. I could manage to do things around it but its when it comes and doesn't lift for days, I really feel defeated. Everything has to be shelved. I just feel everything is beyond my reach, beyond my control, I suppose.

\section{Discussion}

The findings clearly demonstrate that the fatigue experienced by the hepatitis $C$ population is multidimensional. Its most distinguishable feature is the existence of two distinct types of fatigue - chronic and idiopathic which appear to be universally experienced. To date, the experience of fatigue has not been studied in any other hepatitis populations. Indeed, the only hepatology population's fatigue that has been attended to in the literature is that of those with primary biliary cirrhosis, but unfortunately this is only in terms of its prevalence and possible correlates (Huet \& Deslauriers, 1996; Huet et al., 1996). This dearth of information prevents the fatigue experienced by those with hepatitis $\mathrm{C}$ being compared with that of any other hepatology population. Indeed, given the acknowledged significant prevalence of fatigue in the chronic illness population as a distinct entity (Wessely et al., 1998), a negligible amount of knowledge on fatigue has been generated inductively. The studies that do exist primarily focus on the fatigue of cancer patients (Ferrell et al., 1996; Glaus et al., 1996; Pearse \& Richardson, 1996; Ream \& Richardson, 1997; Rose et al., 1998; Small \& Lamb, 1999). Despite this, some similarities can be drawn between hepatitis-associated fatigue and that experienced by other populations. It is multidimensional in nature, with similar dimensions being described, although the significance that the various populations attribute to each dimension is not known at this stage. It would also seem that the physical element of fatigue is experienced universally as a whole-body-sensation. Some elements of hepatitis C associated fatigue, such as 'aching', do not appear to be a universal experience, although they are evident in some patient populations (Schaefer \& Potylcycki, 1993; Ream \& Richardson, 1997). Weakness, another attribute of hepatitis $\mathrm{C}$ fatigue, was also found in a German cancer population (Glaus, 1996). From the qualitative literature available, it appears that the fatigue of various patient populations shares many commonalties but differs in some aspects. Further in-depth study is required before any firm inferences can be drawn.

While conceding this dearth of information, it is accepted that in any one situation there are many potential mechanisms that contribute to fatigue in chronic illness. The most unambiguous categorization of these potential mechanisms is into (i) specific biological mechanisms such as disease activity and treatment and (ii) general mechanisms such as depression, sleep disturbances and pain (Wessley et al., 1998). The original cause of fatigue in a disease may differ from factors which perpetuate it. In patients with chronic systemic diseases such as hepatitis $\mathrm{C}$, it is likely that fatigue is first experienced as a direct result of the disease process and then as a corollary of the disease as it becomes more chronic, with secondary factors such as inactivity, other symptoms and disability perpetuating the fatigue.

Hepatology nurses are the health care professionals with the principal responsibility for assisting hepatitis C 
patients to manage their fatigue. They therefore require in-depth knowledge of the experience of the symptom. In order to attain this knowledge they undertake further research, both as a sole activity and in collaboration with others, to ascertain what are the primary and secondary factors in relation to the fatigue experience and how they are linked. The study detailed in this paper could serve as a starting point. It will also provide a proportion of the knowledge required to begin designing and/or instigating appropriate interventions that allow those affected to live with their fatigue in a proactive manner. When the results of recent studies addressing the prevalence of fatigue in the hepatitis $\mathrm{C}$ population are taken into account, the need to develop effective fatigue interventions is very apparent. Prevalence rates ranging from $67 \%$ to $92 \%$ have been reported from studies carried out in diverse locations, with varying sources of $\mathrm{HCV}$ infection and disease severity (Ahmad et al., 1999; Barkhuizen et al., 1999; Goh et al., 1999; Tanguy et al., 1999; Glacken, 2000).

Surprisingly, although many interventions are suggested to relieve fatigue, to date few have been subjected to empirical testing (Portenoy \& Itri, 1999; Ream \& Richardson, 1999). The literature suggests that because of the multidimensional, multifactorial nature of hepatitis $C$ fatigue, a multimodal intervention that could be tailored to the individual may be the most appropriate (Lorig et al., 1994; Ream \& Richardson, 1999; van Mens-Verhulst et al., 1999). This may include, when all the contributing factors to the fatigue experience have been identified, both pharmacological and non-pharmacological components. An interdisciplinary approach may also be required. To date, pharmacological therapies for fatigue associated with medical conditions have not been subjected to rigorous evaluation, although advancements have been made in the multiple sclerosis population, where the antiviral agent, amantadine hydrocloride, is proving effective (Murray, 1985). Reflecting the newness of hepatitis C, negligible research has been carried out, although, through a casestudy approach, long-term ondansetron has been found to ameliorate hepatitis C fatigue (Jones, 1999). The nonpharmacological component of intervention could take an eclectic approach and include empirically supported strategies such as those addressing energy conservation, sleep management, nutrition support, exercise and psychotherapeutic strategies (Chadler et al., 1997; Gerber et al., 1987; Neuberger et al., 1997; Price \& Couper, 2001).

Hepatology nurses should appreciate that management of fatigue should include a comprehensive evaluation that assesses severity (Portenoy \& Itri, 1999; Tiesinga et al., 1999). Fatigue is a dynamic process that often requires changes in strategies over time. The changes may emanate from a change in the nature of fatigue itself or in response to the individual's lack of acceptance of a strategy or desire to try something new. The emergence of new empirically based knowledge may also herald the introduction of new strategies or combinations. It should also be recognized that the success of any fatigue management programme will depend on many factors, including the quality of the client-practitioner partnership, and that truly listening to the patient, as was attempted in this inquiry, is the basis for high quality relationships.

\section{Acknowledgements}

Michele Glacken was a recipient of a University of Ulster Vice Chancellor's Scholarship in 1997 in support of a PhD programme that included this study. Miscellaneous costs were funded by the participating hospital.

\section{References}

Ahmad I., Owens D., Ahmed W., Khan H., Walker M. \& Anderson G. (1999) To assess the quality of life and symptoms in chronic hepatitis $\mathrm{C}$ virus (HCV) infection in the absence of cirrhosis. Gut 44(Suppl. 1), W216.

Barkhuizen A., Rosen H.R., Wolf S., Flora K., Benner K. \& Bennett R. (1999) Musculoskeletal pain and fatigue are associated with chronic hepatitis C. American Fournal of Gastroenterology 94, 1355-1360.

Cauch-Dudek K., Abbey S., Stewart D.E. \& Heathcote E.J. (1998) Fatigue in primary biliary cirrhosis. Gut 4, 705-710.

Chadler T., Wallace P. \& Wessely S. (1997) Self-help treatment of chronic fatigue in the community: a randomized controlled trial. British Journal of Health Psychology 2(3), 189-197.

Charmaz K. (1995) Between positivism and postmodernism: implications for methods. Studies in Symbolic Interaction 17, 43-72.

Dana F., Becherer P.R. \& Bacon B.R. (1994) Hepatitis C virus. What recent studies can tell us. Postgraduate Medicine 95(121-122), 125-130.

Desmet V.J., Gerber M., Hoofnagle J.H., Manns M. \& Scheuer P.J. (1994) Classification of chronic hepatitis: diagnosis, grading and staging. Hepatology 19, 1513-1520.

Di Bisceglie A.M., Conjeevaram H.S., Fried M.W., Sallie R., Park Y., Yurday-din C. \& Swain M. (1995) Ribarvarin as therapy for chronic hepatitis C. A randomised double-blind, placebocontrolled trial. Annals of Internal Medicine 123, 897-903.

Dietrich R., Bachmann C. \& Lauterburg B.H. (1990) Exercise induced hyperammoniemia in patients with compensated liver disease. Scandinavian Fournal of Gastroenterology 25, 329-334.

Dolan M. (1997) The Hepatitis C Handbook. Catalyst Press, London.

Eidelman D. (1980) Fatigue: towards an analysis and a unified definition. Medical Hypotheses 6, 517-526.

Fattovich G., Giustina G., Degos F., Tremolda F., Diodati G., Almasio P., Nevens F., Solinas A., Mura D., Brouwer J.T., Thomas H., Njapoum C., Casarin C., Bonetti P., Fuschi P., Basho J., Tocco A., Bhalla A., Galassini R., Noventa F., Schalm S.W. \& 
Realdi G. (1997) Morbidity and mortality in compensated cirrhosis type C: a retrospective follow-up study of 384 patients. Gastroenterology 112, 463-472.

Ferrell B.R., Grant M., Dean G.E., Funk B. \& Ly J. (1996) 'Bone Tired': the experience of fatigue and its impact on quality of life. Oncology Nursing Forum 23, 1539-1547.

Gerber L., Schulman B., Smith C., Thornton B., Liang M., Cullen K., Stevens M.B. \& Gilbert N. (1987) Patient education program to teach energy conservation behaviors to patients with rheumatoid arthritis: a pilot study. Archives of Physical Medicine and Rehabilitation 68, 442-445.

Gift A.G. (1997) Clarifying Concepts in Nursing Research. Springer Publishing Co., California.

Glacken M. (2000) Fatigue in the hepatitis C population. Unpublished $\mathrm{PhD}$ Thesis, University of Ulster, Ulster.

Glacken M., Kernohan G. \& Coates V. (2001) Diagnosed with hepatitis C: a descriptive-exploratory study. International fournal of Nursing Studies 38, 107-116.

Glaus A. (1996) Fatigue in patients with cancer. Unpublished $\mathrm{PhD}$ Thesis, University of Surrey, Surrey.

Glaus A., Crow R. \& Hammond S. (1996) A qualitative study to explore the concept of fatigue/tiredness in cancer patients and in healthy individuals. Support Care Cancer 4, 82-96.

Goh J., Coughlan B., Quinn J., O'Keane J.C. \& Crowe J. (1999) Fatigue does not correlate with the degree of hepatitis or the presence of autoimmune disorders in chronic hepatitis C. European Fournal of Gastroenterology and Hepatology 11, 833838.

Hoofnagle J.H. (1997) Hepatitis C: the clinical spectrum of disease. Hepatology 26, 15S-20S.

Huet P.-M. \& Deslauriers J. (1996) Impact of fatigue on quality of life of patients with primary biliary cirrhosis. Gastroenterology 110, A1215.

Huet P.-M., Deslauriers J., Faucher C. \& Charbonneau J. (1996) Fatigue, mental health and depression in patients with primary biliary cirrhosis. Hepatology 24, 167A.

International Council of Nurses (1996) Ethical Guidelines for Nursing Research. ICN, Geneva.

Jones E.A. (1995) Fatigue associated with chronic liver disease: a riddle wrapped in a mystery inside an enigma. Hepatology 22, 1606-1608.

Jones E.A. (1999) Relief from profound fatigue associated with chronic liver disease by long-term ondansetron therapy. Lancet 354(9176), 397.

Kenny-Walsh E. (1999) Clinical outcomes after hepatitis C infection from contaminated anti-D immune globulin. New England Fournal of Medicine 340, 1228-1233.

Kuratsune H., Yamaguti K., Lindh G., Takahashi M., Machii T., Matsumura K., Takaishi J., Kawata S., Langstrom B., Kanakura Y., Kitani T. \& Watanabe Y. (1998) Low levels of serum acylcarnitine in chronic fatigue syndrome and chronic hepatitis $\mathrm{C}$, but not seen in other diseases. International fournal of Molecular Medicine 2, 51-56.

Lee D.H., Jamal H., Regenstein F.G. \& Perrillo R.P. (1997) Morbidity of chronic hepatitis $\mathrm{C}$ as seen in a tertiary care medical centre. Digestive Diseases and Sciences 42, 186-191.

Lewis G. \& Wessely S. (1992) The epidemiology of fatigue: more questions than answers. Fournal of Epidemiology and Community Health 46, 92-97.
Lorig K., Holman H., Sobel D., Laurent D., Gonzalez V. \& Minor M. (1994) Living a Healthy Life with Chronic Conditions. Bull Publishing Co., Pao Alto, CA.

Mahony J. (1998) A Medical Blunder Wrecked my Life. MarieClare (UK edition). February, pp. 157-158.

van Mens-Verhulst J., van Dijkum C., Lam N. \& van Kuijk E. (1999) Dealing with fatigue: the importance of health-related action patterns. Patient Education and Counselling 36, 65-74.

Monks J. (1989) Experiencing symptoms in chronic illness: fatigue in multiple sclerosis. International Disability Studies 11, 78-83.

Morse J.M., Hupcey J.E., Mitcham C. \& Lenz E.R. (1997) Choosing a strategy for concept analysis in nursing research moving beyond Wilson. In Clarifying Concepts in Nursing Research (Gift AG, ed.). Springer Publishing Co., New York, pp. 73-95.

Murray T.J. (1985) Amantadine therapy for fatigue in multiple sclerosis. Canadian Fournal of Neurological Sciences 12, 251-254.

Neuberger G.B., Press A.N., Linsley H.B., Hinton R., Cagle P.E., Carlson K., Scott S., Dahl J. \& Kramer B. (1997) Effects of exercise on fatigue, aerobic fitness, and disease activity measures in persons with Rheumatoid Arthritis. Research in Nursing and Health 20(3), 195-204.

Paterson B.L. (1994) A framework to identify reactivity in qualitative research. Western fournal of Nursing Research 16, 310-316.

Pearse S. \& Richardson A. (1996) Fatigue in cancer: a phenomenological perspective. European Fournal of Cancer Care 5, 111-115.

Plevris J.N. \& Blair C. (1997) Chronic fatigue is associated with increased interleukin-6 levels in patients with chronic liver disease. Hepatology 26(Suppl. 2), 583A.

Portenoy E.K. \& Itri L.M. (1999) Cancer-related fatigue: guidelines for evaluation and management. Oncologist 4(1), 1-10.

Price J.R. \& Couper J. (2001) Cognitive behaviour therapy for adults with chronic fatigue syndrome. The Cochrane Library (Oxford), 4.

Prince M., Ashley D., Edwards N., Mitchison H., Bramble M., James O. \& Jones. D. (1999) Fatigue significantly impairs the quality of life of patients with primary biliary cirrhosis. Hepatology 30, 1613.

Ream E. \& Richardson A. (1997) Fatigue in patients with cancer and chronic obstructive airways disease: a phenomenological enquiry. International Fournal of Nursing Studies 34, 44-53.

Ream E. \& Richardson A. (1999) Continuing education. From theory to practice: designing interventions to reduce fatigue in patients with cancer. Oncology Nursing Forum 26(8), 1295-1305.

Rose L., Pugh L.C., Lears K. \& Gordon D.L. (1998) The fatigue experience: persons with HIV infection. Fournal of Advanced Nursing 28, 295-304.

Schaefer K. \& Potylcycki M. (1993) Fatigue associated with congestive heart failure: use of. Levine's Conservation model. Fournal of Advanced Nursing 18, 260-268.

Shakil A.O., Conry-Contilena C., Alec H.J., Hayaski P., Kleiner D.E., Tedeschni V. \& Krawczynski K. (1995) Volunteer blood donors with antibody to hepatitis $\mathrm{C}$ virus. Clinical, biochemical, virologic and histologic features. Annals of Internal Medicine 123, $330-337$.

Silverman D. (1993) Interpreting Qualitative Data: Methods for Analysing Talk, Text and Interaction. Sage Publications, London.

Small S. \& Lamb M. (1999) Fatigue in chronic illness: the experience of individuals with chronic obstructive pulmonary disease and with asthma. Fournal of Advanced Nursing 30, 469-478. 
Spray G. (1998) Blood, Sweat and Tears. The Hepatitis C Scandal. Wolfhound Press, Dublin.

Strader D.B. \& Seeff L.B. (1996) The natural history of chronic hepatitis infection. European Journal of Gastroenterology and Hepatology 8, 324-328.

Strauss A.L. \& Corbin J. (1990) Basics of Qualitative Research: Grounded Theory Procedures and Techniques. Sage Publications, Inc., Newbury Park, CA.

Swain M.G. \& Maric M. (1995) Defective corticotropin-releasing hormone mediated neuroendocrine and behavioural responses in cholestatic rats: implications for cholestatic liver disease-related sickness behaviour. Hepatology 22, 1560-1564.

Swain M.G. \& Maric M. (1997) Improvement in cholestasis associated fatigue with a serotonin receptor agonist using a novel rat model of fatigue assessment. Hepatology 25, 291-294.

Tanguy G., Remy A.-J., Hyrailles V., Daures J.-P. \& Larrey D. (1999) Effects of antiviral treatment on the quality of life in patients with chronic hepatitis C. Hepatology 30, 1902.
Tiesinga L.J., Dassen T.W.N., Halfens R.J.G. \& van den Heuvel W.J.A. (1999) Factors related to fatigue: priority of interventions to reduce or eliminate fatigue and the exploration of a multidisciplinary research model for further study of fatigue. International Fournal of Nursing Studies 36(4), 265-280.

Tong M.J., El-Ferra N.S. \& Reikes A.R. (1995) Clinical outcomes after transfusion associated hepatitis C. Nem England Fournal of Medicine 332, 1463-1466.

Wessely S., Hotopf M. \& Sharpe M. (1998) Chronic Fatigue and its Syndromes. Oxford University Press, Oxford.

World Health Organisation (1997) WHO Weekly Epidemiological Record (WER) 74(46), 341-349.

Younossi Z.M., O’Neil M., Kiwi M.L., Rosian R., Larive B. \& Calabrese L. (1998) Hepatitis C: health-related quality of life, rheumatologic, virologic and histologic outcomes. Gastroenterology 114, L0704. 